\title{
Short Note: Genotype-Environment Interactions for Coastal Douglas-fir Grown to 21 Years Across Western Washington State, USA
}

\author{
By Christine A. Dean ${ }^{1), *)}$
}

(Received $17^{\text {th }}$ November 2007)

\begin{abstract}
This study involves polymix families of coastal Douglas-fir (Pseudotsuga menziesii (Mirb.) Franco var. menziesii) that were created by crossing parents selected from the Cascade, Longview, Twin Harbors and Vail wild populations of western Washington State. Eight to 10 female parents from each population were crossed using pollen-mixes of males from either the same or different populations. In 1985 these polymix families were planted across six genetic tests located in Cascade, Longview and Twin Harbors (two tests per region). Variance components are reported for over-bark breastheight diameter measured at 21 years (DBH21).

Genotype $\mathrm{x}$ environment (GE) interactions involving different wild populations of Douglas-fir accounted for little variation in DBH21 across the western Washington regions studied. Interaction involving female parents nested within populations was the most important GE effect; explaining $2 \%$ of total variation in DBH21. However, this interaction was of limited practical importance since the superior female parents for DBH21 generally showed good stability across tests. Results from this study support selection of superior coastal Douglasfir genotypes that can produce strong, stable growth across a range of site environments encountered in western Washington.
\end{abstract}

Key words: Coastal Douglas-fir, genotype x environment, genetic stability, breast-height diameter.

\section{Introduction}

Genetic improvement of coastal Douglas-fir (Pseudotsuga menziesii var. menziesii) has been associated with movement of improved seeds and seedlings across different parts of the geographic range of the species. This movement of seed across regions and the closely associated subject of genotype $\mathrm{x}$ environment (GE) interactions has been discussed by many authors including Silen and Wheat (1979), White and Ching (1985), Campbell (1986), Stonecypher (1990) and DeAn (2007). The benefit of using a suite of superior genotypes (seed orchard families) across different geographic regions is simply to capture greater potential gain across more plantation area. Of course, this potential gain can only be realized with reasonably stable genotypes that are well buffered across the different site conditions (i.e. limited GE effects).

Weyerhaeuser Company manages an advanced breeding program of coastal Douglas-fir that has entered its third-generation of improvement and continues to supply superior seed from production orchards. This

\footnotetext{
1) Present address: Weyerhaeuser Company, PO Box 9777, Federal Way, WA 98063-9777, USA.

*) Corresponding author: Christine.Dean@Weyerhaeuser.com
}

improvement program was initially partitioned into the breeding regions of Cascade, Longview, Twin Harbors and Vail in Washington State; and Coos Bay and Springfield in Oregon (DEAN, 2007). The study reported here (known as the "Washington Wide Adaptability" study WWA) is one of the long term research studies that are part of Weyerhaeuser's tree improvement program and includes six first-generation genetic field tests established in 1985 across Cascade, Longview and Twin Harbors (two tests per region); and last measured for growth at 21 years. DEAN (2007) reported eight and 13year growth results of the same WWA study. One of the main objectives of this study is to examine the stability over time of populations, parents and families of coastal Douglas-fir when grown across low elevation (below $600 \mathrm{~m}$ ) sites in western Washington State.

\section{Materials and Methods \\ Site, Establishment and Silviculture}

The results reported here involve six genetic field tests that are part of Weyerhaeuser's first-generation breeding of coastal low-elevation $(<600 \mathrm{~m})$ Douglas-fir. The tests are located in Cascade, Longview and Twin Harbors regions. The six tests were planted in 1985 using containerized seedlings at 3,020 trees per hectare (site and establishment details given in DEAN, 2007).

In 1998 (or 13 years after planting) the six WWA genetic tests were thinned to 50 percent by removing one of the interlocking layers in the non-contiguous field design (described under Field Design).

\section{Genetic Material and Mating Design}

The WWA study involves female and male coastal Douglas-fir (Pseudotsuga menziesii (Mirb.) Franco var. menziesii) parents from Cascade, Longview, Twin Harbors and Vail regional populations of western Washington. Eight to 10 female parents from each population were crossed in grafted orchards using pollen-mixes of males from either the same ("intra-population") or different ("inter-") regional populations; creating total 144 families (Table 1). The pollen-mixes representing each regional population included 11 to 12 male parents. At the time of crossing the female and pollen parents were all in the top $50 \%$ of clones for growth measured across then current genetic tests. Some parents served as both male and female but no selfing was allowed in the polymix matings.

\section{Field Design}

Each test was based on six complete randomised replications that each originally contained four complete ran- 
Table 1. - Polymix crossing design used to create the 144 families analysed in this WWA study. "Intra-population" families are crosses between parents of the same population (Cascade, Longview, Twin Harbors or Vail), and "inter-" are crosses between parents from different populations.

\begin{tabular}{|c|c|c|c|c|}
\hline \multirow{2}{*}{$\begin{array}{l}\text { Female } \\
\text { parents } \\
\text { (by region) }\end{array}$} & \multicolumn{4}{|c|}{ Washington pollen-mixes (by region) } \\
\hline & $\begin{array}{c}\text { Cascade } \\
\text { (12-parent } \\
\text { mix })\end{array}$ & $\begin{array}{l}\text { Longview } \\
\text { (11-parent } \\
\text { mix })\end{array}$ & $\begin{array}{c}\text { Twin } \\
\text { Harbors } \\
\text { (12-parent } \\
\text { mix) }\end{array}$ & $\begin{array}{c}\text { Vail } \\
\text { (11-parent } \\
\text { mix })\end{array}$ \\
\hline $\begin{array}{l}\text { Cascade: } \\
\text { CA-01 to CA-08 }\end{array}$ & $\begin{array}{l}\text { intra-pop. } \\
8 \text { families }\end{array}$ & $\begin{array}{l}\text { inter- } \\
8 \text { families }\end{array}$ & $\begin{array}{l}\text { inter- } \\
8 \text { families }\end{array}$ & $\begin{array}{l}\text { inter- } \\
8 \text { families }\end{array}$ \\
\hline $\begin{array}{l}\text { Longview: } \\
\text { LV-09 to LV-18 }\end{array}$ & $\begin{array}{l}\text { inter- } \\
10 \text { families }\end{array}$ & $\begin{array}{l}\text { intra-pop. } \\
10 \text { families }\end{array}$ & $\begin{array}{l}\text { inter- } \\
10 \text { families }\end{array}$ & $\begin{array}{l}\text { inter- } \\
10 \text { families }\end{array}$ \\
\hline $\begin{array}{l}\text { Twin Harbors: } \\
\text { TH-19 to TH-26 }\end{array}$ & $\begin{array}{l}\text { inter- } \\
8 \text { families }\end{array}$ & $\begin{array}{c}\text { inter- } \\
8 \text { families }\end{array}$ & $\begin{array}{l}\text { intra-pop. } \\
8 \text { families }\end{array}$ & $\begin{array}{c}\text { inter- } \\
8 \text { families }\end{array}$ \\
\hline $\begin{array}{l}\text { Vail: } \\
\text { VA-27 to VA-36 }\end{array}$ & $\begin{array}{c}\text { inter- } \\
10 \text { families }\end{array}$ & $\begin{array}{c}\text { inter- } \\
10 \text { families }\end{array}$ & $\begin{array}{c}\text { inter- } \\
10 \text { families }\end{array}$ & $\begin{array}{l}\text { intra-pop. } \\
10 \text { families }\end{array}$ \\
\hline
\end{tabular}

domised interlocking main blocks (described by DEAN, 2007). Each polymix family was represented by one single-tree plot per interlocking block; giving total 24 trees per family. The interlocking design facilitated a systematic and yet "random" $50 \%$ thinning of the field tests; carried out in 1998.

\section{Measurements}

Trees were measured for stem diameter over-bark at breast height $(137 \mathrm{~cm})$ at 21 years $(\mathrm{DBH} 21)$ after planting.

\section{Statistical Methods}

Analyses were made with ASREML (GILMOUR et al., 2006) and the following model fitted to individual tree data for 144 polymix families across six genetic tests - (1)

Trait $_{\text {ghijklmn }}=\mu+$ Female PoP $_{g}+$ POLlen PoP $_{h}+$

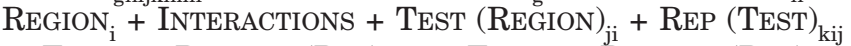
+ Female Parent $(\mathrm{Pop})_{\operatorname{lm}}+$ Female Parent (Pop) $\mathrm{x}$ $(\text { Region })_{\text {lmi }}+$ Female Parent (Pop) x Test $(\text { Region })_{\text {Imij }}+$ RESIDUAL $_{\text {ghijklmn }}$

where TRAIT $_{\text {ghijklmn }}$ is the DBH21 of an individual tree; $\mu$ is a fitted mean; Female PoP ${ }_{g}$ and Pollen POP $_{h}$ represent the effects of population of origin of the female and pollen parents, assumed to be fixed effects; REGION ${ }_{i}$ is the regional location of the genetic tests, assumed fixed; INTERACTIONS represent all possible interactions among these previously mentioned fixed effects; TEST (REGION) is the random effect of genetic tests nested within each region; REP (TEST) ${ }_{\text {kij }}$ random effect of replications within test; Female Parent (POP) ${ }_{\mathrm{lm}}$ random effect of female parents within each population; FEMALE PARENT (POP) $\mathrm{x}$
(Region) $)_{\text {lmi }}$ and Female Parent (Pop) x Test (REgion) Imij are their interactions; and $\mathrm{RESIDUAL}_{\text {ghijklmn }}$ is a residual error.

Trees with residual values for $\mathrm{DBH} 21$ of more than 3.5 residual standard deviations in absolute value after running the model once, were omitted and the data reanalysed.

\section{Results and Discussion}

\section{Analyses of Variance}

Main Effects: Table 2 presents variance components from ASREML analyses of DBH21 across the six WWA tests. Female Parent (PoP) was the most important main effect in explaining $3.4 \%$ of the total variance of DBH21 across the tests. The population of coastal Douglas-fir parents in the WWA study (i.e. Cascade, Longview, Twin Harbors and Vail sources) accounted for no more than $1 \%$ of total variation in DBH21 $(0.4 \%$ for Female Pop and $1.0 \%$ for Pollen Pop; Table 2).

Table 2 also presents percent contributions of variance components for breast-height diameter over-bark at 13 years (DBH13); taken from DEAN (2007). DBH13 was measured immediately prior to the $50 \%$ thinning of the six tests that involved the systematic removal of interlocking-blocks within replications. It is evident from Table 2 that thinning, together with the subsequent pattern of growth between 13 and 21 years, has substantially reduced the relative importance of TEST (REGION) and REPLICATION (TEST) main effects in the analyses.

Broad-Sense GE: The GE interactions have been classed as "broad" and "narrow-sense" in terms of genotype; following MATHESON and CoTTERILL (1990) and DEAN (2007). "Broad-sense" interactions are defined as 
Table 2. - Variance components (and standard errors SE) from ASREML analyses of individual tree data for diameter over-bark at 21 years (DBH21) for coastal Douglas-fir polymix families from Cascade, Longview, Twin Harbors and Vail populations when grown across six genetic tests in Cascade, Longview and Twin Harbors regions. Also given is the percent contribution of each component to the overall variation among individual trees for DBH21 and diameter over-bark at 13 years (DBH13); the later taken directly from DEAN (2007).

\begin{tabular}{|c|c|c|c|c|}
\hline \multirow[t]{2}{*}{ Source of Variation } & \multicolumn{3}{|c|}{ DBH21 } & \multirow{2}{*}{$\begin{array}{l}\text { DBH13 } \\
\text { Cont- } \\
\text { ribution } \\
(\%)\end{array}$} \\
\hline & $\begin{array}{l}\text { Vari- } \\
\text {-ance } \\
(\mathrm{cm})\end{array}$ & $\begin{array}{l}\mathrm{SE} \\
(\mathrm{cm})\end{array}$ & $\begin{array}{l}\text { Cont- } \\
\text { ribution } \\
(\%)\end{array}$ & \\
\hline \multicolumn{5}{|l|}{ Main Effects ${ }^{A}$ : } \\
\hline REGION & $0.391^{\mathrm{ns}}$ & 0.543 & $2.1 \%$ & $0.2 \%$ \\
\hline TEST (REGION) & $0.153^{\mathrm{ns}}$ & 0.202 & $0.8 \%$ & $5.8 \%$ \\
\hline REPLICATION (TEST) & $0.414 * *$ & 0.134 & $2.2 \%$ & $10.4 \%$ \\
\hline FEMALE POP & $0.066^{\mathrm{ns}}$ & 0.129 & $0.4 \%$ & $0.5 \%$ \\
\hline POLLEN POP & $0.188^{\mathrm{ns}}$ & 0.186 & $1.0 \%$ & $0.3 \%$ \\
\hline FEMALE PARENT (POP) & $0.636^{* *}$ & 0.196 & $3.4 \%$ & $2.1 \%$ \\
\hline \multicolumn{5}{|l|}{ Genotype x Genotype Effects: } \\
\hline FEMALE POP x POLLEN POP & $0.008^{\mathrm{ns}}$ & 0.020 & $0.0 \%$ & $0.1 \%$ \\
\hline \multicolumn{5}{|l|}{ Broad-Sense Genotype x Environment ${ }^{\text {B }}$ : } \\
\hline FEMALE POP x REGION & $0.000^{\mathrm{ns}}$ & na & $0.0 \%$ & $0.0 \%$ \\
\hline POLLEN POP x REGION & $0.083^{\mathrm{ns}}$ & 0.064 & $0.4 \%$ & $0.3 \%$ \\
\hline FEMALE POP x POLLEN POP x REGION & $0.000^{\mathrm{ns}}$ & na & $0.0 \%$ & $0.0 \%$ \\
\hline \multicolumn{5}{|l|}{ Narrow-Sense Genotype x Environment ${ }^{B}$ : } \\
\hline FEMAle PARENT (POP) x TEST (REGION) & $0.374 * *$ & 0.092 & $2.0 \%$ & $2.1 \%$ \\
\hline FEMALE PARENT (POP) x REGION & $0.000^{\mathrm{ns}}$ & na & $0.0 \%$ & $0.0 \%$ \\
\hline RESIDUAL $^{\mathrm{A}}$ & 16.451 & 0.273 & $87.7 \%$ & $78.1 \%$ \\
\hline
\end{tabular}

${ }^{n s}$ Not significant at the $5 \%$ level of probability, $* *$ significant at a level of $<1 \%$.

those involving the different populations of coastal Douglas-fir studied (e.g. FEMALE or POLLEN POP interacting with REGION or TEST (REGION)). "Narrow-sense" interactions are at the level of female parent (e.g. FEMALE PARENT (PoP) interacting with REGION or TEST (REGION)).

Broad-sense GE effects do not appear to be important for DBH21 of the Douglas-fir populations grown across the western Washington regions studied here. The strongest broad-sense GE effect explained only $0.4 \%$ of variation in DBH21 and involved POLLEN POP x REGION. The corresponding FEMALE POP $\mathrm{x}$ REGION interaction accounted for almost no variation in $\mathrm{DBH} 21$. It is worth noting that average rotation length of commercial plantations of coastal Douglas-fir on higher productivity sites of Washington and Oregon States may be around 40-50 years. Hence the 21-year measurement of growth reported here may be approaching half-rotation for general industry-wide plantations.

DEAN (2007) also observed that broad-sense GE effects were relatively unimportant for $\mathrm{DBH} 13$ across this WWA study (Table 2). WHITE and CHING (1985) found relatively little broad-sense population $\mathrm{x}$ environment interaction in a study involving 14 populations of coastal Douglas-fir grown to 25 years across five sites in south-west Oregon.
Narrow-Sense GE: The interaction of Female PaRent (POP) x TEST (REGION) accounted for $2 \%$ of variation in DBH21 and was by far the most important GE effect in the WWA study (Table 2). However, in spite of this interaction, most female parents exhibited good stability for DBH21 across tests. For example, in results not reported, none of the top four of 36 (ca. top 10\%) female parents for DBH21 across all six tests ranked outside the top quarter of female parents in any individual test. There were some unstable female parents but they were the exception in this study. The other narrow-sense GE interaction of FEMALE PARENT (POP) $x$ REGION accounted for no variation in DBH21 (Table 2).

The narrow-sense GE effects deal with the issue of movement of genetically improved seed families across regions. The Female Parent (Pop) x Test (Region) or REGION reported here for DBH21 suggest that strong genetic gains can be achieved from the movement of improved seed families across low-elevation areas of western Washington. In terms of genetic improvement programs of coastal Douglas-fir it does not seem necessary to have different breeding lines for different regions (DEAN, 2007).

Genotype $x$ Genotype $(G G)$ : This study permits analyses of GG effects involving inter- and intra-population 
crossings of coastal Douglas-fir. Female PoP x POLLEN PoP effects accounted for no variation in DBH21 (Table 2).

\section{Conclusions}

The WWA study suggests that broad-sense GE effects at the population level are not particularly important for coastal Douglas-fir growing across low-elevation sites in western Washington State through 21 years.

The narrow-sense interaction of FEMALE PARENT (POP) $x$ REGION accounted for no variation in DBH21. The other narrow-sense GE effect of FEMALE PARENT (PoP) $\mathrm{x}$ TEST (REGION) was the most important interaction in this study. However, the magnitude of this interaction does not appear sufficient to prevent reliable selection of coastal Douglas-fir for strong stable performance across the low elevation environments studied.

\section{Acknowledgements}

With many thanks to current and past members of the Tree Improvement Team at Weyerhaeuser including especially: Jerry Chapman, Jess DANiels, MARK HefFner, Gary Helland, Ed Herold, Jim Reno and Roy STONECYPHER who have been responsible for the installation, diligent long-term care and maintenance of these study sites and the measurement and management of the ensuing high quality data.

\section{Literature Cited}

CAMPBElL, R. K. (1986): Mapped genetic variation of Douglas-fir to guide seed transfer in southwest Oregon. Silvae Genet. 35: 85-95.

DEAN, C. A. (2007): Genotype and population performances and their interactions for growth of coastal Douglas-fir in western Washington. For. Sci. 53: 463-472.

Gilmour, A. R., B. J. Gogel, B. R. Cullis and R. ThompSON (2006): ASREML User Guide Release 2.0 VSN International Ltd, Hemel Hempstead, HP1 1ES, UK.

Matheson, A. C. and P. P. CotTerill (1990): Utility of genotype $\mathrm{x}$ environment interactions. For. Ecol. Manage. 30: $159-174$.

Silen, R. R. and J. G. WheAT (1979): Progressive tree improvement program in coastal Douglas-fir. J. For. 77: $78-83$.

StonecypheR, R. W. (1990): Assessing effects of seed transfer for selected parents of Douglas-fir: Experimental methods and early results. In: Proc. of Joint Meet. of Western Forest Genetics Association and IUFRO Working Parties S2.02-05,06,12 and 14. Olympia, WA.

White, T. L. and K. K. ChInG (1985): Provenance study of Douglas-fir in the Pacific Northwest region. IV. Field performance at age 25 years. Silvae Genet. 34: 84-90.

\title{
Growth Rhythm Parameters as Components of Hybrid Vigour in Young Seedlings of Hybrid Larch (Larix decidua $x$ L. kaempferi)
}

\author{
By LuC E. PÂQUES*) \\ INRA-UR588, Unité Amélioration, Génétique et Physiologie des arbres forestiers, \\ F-45160 Orléans (France)
}

(Received $22^{\text {th }}$ November 2007)

\begin{abstract}
Heterosis for growth traits was investigated on 2-yrold seedlings from related intra- and inter-specific progenies collected in hybridisation seed orchards combining Larix decidua (EL) and L. kaempferi (JL). Following taxa identification, seedlings phenology and growth were observed over a complete growing season in two experiments. Start, cessation, duration and rates of growth for the different taxa were explored in relation to hybrid vigour. Variable levels of heterosis were observed, depending on the genetic background of the parental species, the species over which superiority was
\end{abstract}

\footnotetext{
*) Tel. +332 384178 21, Fax: +33 2384178 79, E-mail: paques@ orleans.inra.fr
}

evaluated, environmental conditions and the traits considered. While significant and consistent differences have been observed between hybrids and their related EL progenies for phenological growth traits, a better timing of the growth rhythm over the growing season together with a greater growth efficiency allowed for a consistently positive heterosis over EL. The situation appeared more complex with JL as heterosis could be either positive or negative. Besides the high variation in heterosis levels, the way heterosis for height built up over the growing season seemed also to be variable according to genetic backgrounds: cumulative constant superiority of the hybrid for growth rhythms along the growing season or greater growth rates during discrete periods of time.

Key words: heterosis, phenology, growth, hybrid larch, Larix. 